\title{
Assignment of Human-Derived CDC Group 1 Coryneform Bacteria and CDC Group 1-Like Coryneform Bacteria to the Genus Actinomyces as Actinomyces neuii subsp. neuii sp. nov., subsp. nov., and Actinomyces neuii subsp. anitratus subsp. nov. GUIDO FUNKE, ${ }^{1 *}$ SIMON STUBBS, ${ }^{2}$ ALEXANDER vON GRAEVENITZ, ${ }^{1}$ AND MATTHEW D. COLLINS ${ }^{2}$ \\ Institute of Medical Microbiology, University of Zürich, $\mathrm{CH}-8028$ Zürich, Switzerland, ${ }^{1}$ and Department of Microbiology, AFRC Institute of Food Research, Reading Laboratory, Reading RG6 2EF, United Kingdom ${ }^{2}$
}

\begin{abstract}
Almost the entire 16S rRNA gene sequences of some strains of CDC group 1 and group 1-like coryneform bacteria, isolated from human sources, were determined. Comparative analysis of the rRNA sequence data revealed that both groups of coryneforms belong to the genus Actinomyces. On the basis of the present molecular findings and previous biochemical studies, we propose a new Actinomyces species, Actinomyces neuii sp. nov., containing Actinomyces neuii subsp. neuii subsp. nov. for CDC group 1 coryneform bacteria and Actinomyces neuii subsp. anitratus subsp. nov. for CDC group 1-like coryneform bacteria.
\end{abstract}

In 1987, Na'was et al. (12) described some aerobically growing coryneform bacteria, isolated from clinical specimens, which were designated CDC (Centers for Disease Control) fermentative coryneform group 1. These nonmotile coryneforms are catalase positive; reduce nitrate; do not hydrolyze urea, esculin, or gelatin; and are characterized by their ability to ferment many carbohydrates (e.g., glucose, maltose, sucrose, lactose, mannitol, and xylose) used in the routine panel for identification of coryneforms. Recently, we reported the isolation, from human sources, of biochemically similar but nevertheless different (e.g., unable to reduce nitrate) bacteria which were referred to as CDC group 1-like coryneform bacteria (7). Both CDC group 1 and group 1-like coryneform bacteria were frequently isolated from abscesses in association with mixed anaerobic flora. Studies of volatile and nonvolatile metabolic and cellular fatty acid patterns as well as the composition of cell wall and membrane components (lack of meso-diaminopimelic acid and mycolic acids) (14) prompted us to suggest that CDC group 1 and group 1-like coryneform bacteria belong to the genus Actinomyces (7). In this report, we have determined the nucleotide sequence of the gene encoding the 16S rRNA of CDC group 1 and group 1-like coryneform bacteria in order to establish their exact phylogenetic position.

\section{MATERIALS AND METHODS}

Bacterial strains. The CDC group 1 coryneform bacterium (strain $97 / 90^{\mathrm{T}}$ ) was isolated from an infected mammary hematoma, and the CDC group 1-like bacterium (strain $50 / 90^{\mathrm{T}}$ ) was obtained from a blood culture. Both isolates were from patients hospitalized in Zürich, Switzerland.

Growth conditions and biochemical tests. Bacteria were grown on Columbia agar base (Becton Dickinson, Cockeysville, Md.) supplemented with $5 \%$ sheep blood at $37^{\circ} \mathrm{C}$ in a

\footnotetext{
* Corresponding author. Mailing address: Institute of Medical Microbiology, University of Zürich, Gloriastrasse 32, CH-8028 Zürich, Switzerland. Phone: 41-1-257-2700. Fax: 41-1-252-8107.
}

$5 \% \mathrm{CO}_{2}$ atmosphere. Cells were harvested after $48 \mathrm{~h}$ of incubation. The biochemical testing methods have been described in detail previously (7). In addition, fermentation of carbohydrates was determined with the API 50CH system (API bioMérieux, Marcy l'Etoile, France). Fermentation reactions were recorded after 5 days of incubation at $37^{\circ} \mathrm{C}$.

Sequence determination of rRNA genes. Total genomic DNA was isolated with a standard minipreparation method outlined by Ausubel et al. (1). A large fragment of the $16 \mathrm{~S}$ rRNA gene was amplified by PCR using the universal primers pA ( 8 to 28 , Escherichia coli numbering [3]) and $\mathrm{pH}^{*}$ (1542 to 1522) (2). Direct sequencing of the amplified product was performed with primers to conserved regions of the rRNA and the Sequenase version 2.0 sequencing kit (U.S. Biochemical Corp.) as described previously (10). The rRNA sequences determined were aligned with those of other published high-G+C-content actinomycetes (EMBL Data Library), and the similarity values were determined with the Beckman Microgenie program (13). Nucleotide substitution rates were calculated (9), and an unrooted phylogenetic tree was produced with the algorithm of Fitch and Margoliash (5, $6)$.

Nucleotide sequence accession number. The nucleotide sequences of the 16S rRNA of strains $97 / 90^{\mathrm{T}}$ and $50 / 90^{\mathrm{T}}$ have been deposited with GenBank (EMBL) under accession no. $\mathrm{X} 71861$ and $\mathrm{X} 71862$, respectively.

\section{RESULTS AND DISCUSSION}

The 16S rRNA genes of the human isolates $97 / 90^{\mathrm{T}}$ (CDC group 1 coryneform bacteria) and $50 / 90^{\mathrm{T}}$ (CDC group 1-like coryneform bacteria) were amplified in vitro, and their nucleotide sequences were determined directly. Figure 1 shows the aligned primary structure of the 16S rRNA of the two strains. The sequences determined consisted of 1,487 to 1,489 nucleotides ranging from positions 31 to $1519(E$. coli numbering). The two new 16S rRNA sequences were compared with those of other high-G+C-content gram-positive bacteria available from the EMBL Data Library. The highest degree of sequence relatedness was shown with members of 
31

97/90 CGAACGCTGGCGGCGTGCTTAACACATGCAAGTCGAACGGGATCCATTGGTGC. . TTGCACTTTTGGTGAGAGTGGCGAACGGGTGAGTAACACGTGAGT 50/90 CGAACGCTGGCGGCGTGCTTAACACATGCAAGTCGAACGGGATCCATTAGCGCTTTTGTGTTTTTGGTGAGAGTGGCGAACGGGTGAGTAACACGTGAGT

97/90 AACCTGCCCTTTTCTTTGGGATAAGCCTGGGAAACTGGGTCTAATACTGGATGTTCCGNCTTCCTCGCATGGGGTTGTTGGAAAGTTTTTTCTGGATT 50/90 AACCTGCCCTTTTCTTTGGGATAAGCCTGGGAAACTGGGTCTAATACTGGATGTTCCGNCTTCCTCGCATGGGGTTGTTGGGAAAGGTTTTTTCTGGATT

97/90 GGGATGGGCTCGCGGCTTATCAGCTTGTTGGTGGGGTGATGGCTTACCAAGGCTTTGACGGGTAGCCGGCCTGAGAGGGTGGTCGGTCACACTGGGACTG 50/90 GGGATGGGCTCGCGGCTTATCAGCTTGTTGGTGGGGTGATGGCTTACCAAGGCTTTGACGGGTAGCCGGCCTGAGAGGGTGGTCGGTCACACTGGGACTG

97/90 AGATACGGCCCAGACTCCTACGGGAGGCAGCAGTGGGGGATATTGCACAATGGACGCAAGTCTGATGCACCGACGTCGTGTGGGGGATGAAGGCCTTCGG 50/90 AGATACGGCCCAGACTCCTACGGGAGGCAGCAGTGGGGGATATTGCACAATGGACGGAAGTCTGATGCACCGACGTCGTGTGGGGGATGAAGGCCTTCGG

97/90 GTTGTAAACTCCTTTCGCCTGCGGAAAAGGCAGGGTTTTGGCCTTGTTGATGGTAGTGGGTAAAGAAGCGCCGGCTCACTACGTGCCAGCAGCCGCGGTA 50/90 GTTGTAAACTCCTTTCGCCCGCGGAAAAGGCAGGGTTTTGGCCTTGTTGATGGTAGTGGGTAAAGAAGCGCCGGCTCACTACGTGCCAGCAGCCGCGGTA

97/90 ATACGTAGGGCGCGAGCGTTGTCCGGAATTATTGGGCGTAAAGGGCTCGTAGGCGGTTTGTCGCGTCTAGCGTTTAAGGCTCGGGCTTAACCCGGGTTTG 50/90 ATACGTAGGGCGCGAGCGTTGTCCGGAATTATTGGGCGTAAAGGGCTCGTAGGCGGTTTGTCGCGTCTAGCGTTTAAGGCTCGGGCTTAACCCGGGTTTG

97/90 CGTTGGGTACGGGCAGGCTTGAGTGCGGTAGGGGTAACTGGAATTCCTGGTGTAGCGGTGGAATGCGCAGATATCAGGAGGAACACCGGTGGCGAAGGCG 50/90 CGTTGGGTACGGGCAGGCTTGAGTGCGGTAGGGGTAACTGGAATTCCTGGTGTAGCGGTGGAATGCGCAGATATCAGGAGGAACACCGGTGGCGAAGGCG

97/90 GGTTACTGGGCCGTTACTGACGCTGAGGAGCGAGAGCGTGGGGAGCGAACAGGATTAGATACCCTGGTAGTCCATGCTGTAAACGTTGGGCACTAGGTGT 50/90 GGTTACTGGGCCGTTACTGACGCTGAGGAGCGAGAGCGTGGGGAGCGAACAGGATTAGATACCCTGGTAGTCCATGCTGTAAACGTTGGGCACTAGGTGT

97/90 GGGGGCTGGTTTCATGGTTCCGCGCCGTAGCTAACGCATTAAGTGCCCCGCCTGGGGAGTACGGCCGCAAGGCTAAAACTCAAAGGAATTGACGGGGGCC 50/90 GGGGGCTGGTTTCATGGTTCCGCGCCGTAGCTAACGCATTAAGTGCCCCGCCTGGGGAGTACGGCCGCAAGGCTAAAACTCAAAGGAATTGACGGGGGCC

97/90 CGCACAAGCGGCGGAGCATGCGGATTAATTCGATGCAACGCGAAGAACCTTACCAAGGCTTGACATGCACCGCGAGACTGCAGAGATGTGGTTGCCTTCG 50/90 CGCACAAGCGGCGGAGCATGCGGATTAATTCGATGCAACGCGAAGAACCTTACCAAGGCTTGACATGCACCGCGAGACTGCAGAGATGTGGTTGCCTTCG

97/90 GGGTGGTGTGCAGGTGGTGCATGGTTGTCGTCAGCTCGTGTCGTGAGATGTTGGTTAAGTCCCGCAACGAGCGCAACCCTTGTCTCATGTTGCCAGCACG 50/90 GGGTGGTGTGCAGGTGGTGCATGGTTGTCGTCAGCTCGTGTCGTGAGATGTTGGTTAAGTCCCGCAACGAGCGCAACCCTTGTCTCATGTTGCCAGCACG

97/90 TTTGGGTGGGGACTCGTGAGAGACTGCCGGGGTTAACTCGGAGGAAGGTGGGGATGACGTCAAATCATGATGCCCCATATGTCTTGGGCTTCACGCATGC 50/90 TTATGGTGGGGACTCGTGAGAGACTGCCGGGGTTAACTCGGAGGAAGGTGGGGATGACGTCAAATCATGATGCCCCATATGTCTTGGGCTTCACGCATGC

97/90 TACAGTGGTGTCTACAGAGGGTTGCTATTCCGTGAGGTTGAGCGAATCTCTTAAAGGGCATCTTGGTTCGGATCGCAGTCTGCAACTCGACTGCGTGAAG 50/90 TACAGTGGTGTCTACAGAGGGTTGCTATTCCGTGAGGTTGAGCGAATCTCTTAAAGGGCATCTTGGTTCGGATCGCAGTCTGCAACTCGACTGCGTGAAG

97/90 GTGGAGTCGCTAGTAATCGCAGATGAGCATTGCTGCGGTGAATACGTTCTCGGGCCTTGTACACACCGCCCGTCACGTCACGAAAGTTGGTAACACCCGA 50/90 GTGGAGTCGCTAGTAATCGCAGATGAGCATTGCTGCGGTGAATACGTTCTCGGGCCTTGTACACACCGCCCGTCACGTCACGAAAGTTGGTAACACCCGA

97/90 AGCCTGTGGCCTAACCTTTTTGGGGGGAGTGGTCGAAGGTGGGGCTAGCGATTGGGACGAAGTCGTAACAAGGTAGCCGTACCGGAAGG 50/90 AGCCTGTGGCCTAACCTTTTTGGGGGGAGTGGTCGAAGGTGGGGCTAGCGATTGGGACGAAGTCGTAACAAGGTAGCCGTACCGGAAGG

FIG. 1. Nucleotide sequences of derived 16S rRNA of $A$. neuii subsp. neuii and $A$. neuii subsp. anitratus.

the genus Actinomyces. Percent similarity values based on a continuous stretch of approximately 1,330 nucleotides (from positions 107 to $1464, E$. coli numbering) of CDC group 1 and group 1-like strains and Actinomyces species are shown in Table 1. Approximately 100 nucleotides at the $5^{\prime}$ end of the rRNA were excluded from these calculations because of incomplete sequence data for some Actinomyces species (15) and to eliminate possible alignment errors because of variations in the length of region V1. A phylogenetic tree constructed from a matrix of derived evolutionary distances showing the interrelationships of the two coryneform isolates and species of the genus Actinomyces is shown in Fig. 2.

Comparative sequence analyses show that the $\mathrm{CDC}$ group

TABLE 1 . 16S rRNA sequence similarity between $A$. neuii and related species

\begin{tabular}{|c|c|c|c|c|c|c|c|c|c|c|c|}
\hline \multirow{2}{*}{\multicolumn{2}{|c|}{ Taxon }} & \multicolumn{10}{|c|}{$\%$ of sequence similarity to $\operatorname{taxon}^{a}$ : } \\
\hline & & 2 & 3 & 4 & 5 & 6 & 7 & 8 & 9 & 10 & 11 \\
\hline 1 & Actinomyces bovis & 94.8 & 95.2 & 87.2 & 88.4 & 91.4 & 90.1 & 88.2 & 88.2 & 88.3 & 85.1 \\
\hline 2 & Actinomyces naeslundii & & 98.1 & 87.2 & 89.0 & 91.3 & 90.6 & 88.1 & 88.1 & 88.2 & 85.4 \\
\hline 3 & Actinomyces viscosus & & & 87.6 & 89.0 & 91.7 & 90.3 & 88.1 & 88.1 & 88.3 & 85.2 \\
\hline 4 & "Actinomyces suis" & & & & 91.2 & 88.1 & 88.5 & 87.8 & 87.7 & 89.5 & 83.6 \\
\hline 5 & Actinomyces pyogenes & & & & & 88.9 & 88.6 & 88.3 & 88.3 & 94.1 & 83.8 \\
\hline 6 & Actinomyces odontolyticus & & & & & & 95.3 & 89.3 & 89.5 & 88.7 & 86.2 \\
\hline 7 & Actinomyces hyovaginalis & & & & & & & 90.0 & 90.2 & 88.5 & 85.4 \\
\hline 8 & Actinomyces neuii subsp. neuii & & & & & & & & 99.7 & 88.6 & 82.4 \\
\hline 9 & Actinomyces neuii subsp. anitratus & & & & & & & & & 88.9 & 82.4 \\
\hline 10 & Arcanobacterium haemolyticum & & & & & & & & & & 83.8 \\
\hline 11 & Bifidobacterium bifidum & & & & & & & & & & \\
\hline
\end{tabular}

${ }^{a}$ Values are based on a comparison of ca. 1,340 nucleotides. With a larger set of data with 1,489 nucleotides (including variable region V1), $A$. neuii subsp. neuii and $A$. neuii subsp. anitratus strains exhibited $99.3 \%$ sequence similarity. 


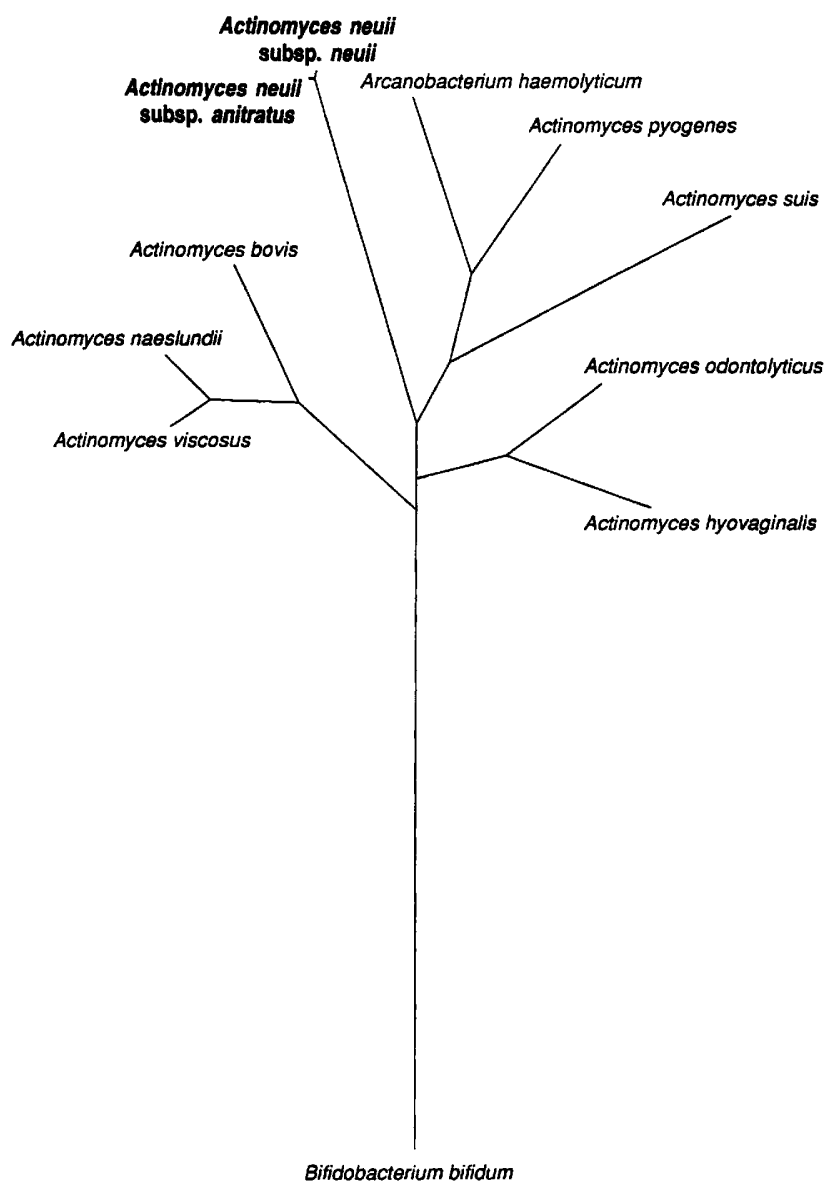

FIG. 2. Unrooted tree showing the phylogenetic interrelationships of $A$. neuii subsp. neuii, $A$. neuii subsp. anitratus, and some other Actinomyces species. The network is based on a comparison of ca. 1,330 nucleotides.
1 and group 1-like strains are members of the genus Actinomyces (Table 1). A high degree of 16S rRNA sequence similarity was also found with Arcanobacterium haemolyticum, although two Actinomyces species (A. hyovaginalis and $A$. odontolyticus) showed higher degrees of similarity to CDC group 1 and group 1-like strains than $A$. haemolyticum. At present, the generic placement of $A$. haemolyticum is critical and needs further investigation. However, CDC group 1 and group 1-like strains are clearly clustered within the confines of the genus Actinomyces. It is evident from sequence similarity values and the treeing program that these two coryneform groups show no specific affinity with other Actinomyces species. In a recent investigation (7), qualitative chromosomal DNA-DNA pairing indicated that CDC group 1 and $C D C$ group 1-like coryneform bacteria might represent distinct genospecies. The finding of a high degree of $16 \mathrm{~S}$ rRNA sequence similarity (99.3\%) between these groups is not inconsistent with these findings but simply demonstrates the close genealogical relatedness of these species. Despite this high overall degree of similarity, the two coryneform isolates could be distinguished by sequences in variable region V1 of their 16S rRNA (five mismatches, two unmatched) (Fig. 1). Partial sequence analysis of additional isolates (viz., CDC group 1 strains $222 / 92$ and 268/92 and CDC group 1-like strains 219/92, $246 / 92$, and 256/92) showed that the sequences of this region were indeed characteristic of the two groups and supports their genospecific distinctiveness. However, at present no quantitative DNA-DNA hybridization data support the proposal of two different species (16). Nevertheless, CDC group 1 and CDC group 1-like strains can be distinguished phenotypically (e.g., by their ability to reduce nitrate) (Table 2). On the basis of the present phylogenetic analysis and phenotypic studies (7), we consider that the CDC group 1 and CDC group 1-like bacteria should be classified as a new species of the genus Actinomyces containing two subspecies. The name Actinomyces neuii subsp. neuii is proposed for CDC group 1 coryneform bacteria, and Actinomyces

TABLE 2. Characteristics for differentiation of $A$. neuii from other Actinomyces species and $A$. haemolyticum ${ }^{a}$

\begin{tabular}{|c|c|c|c|c|c|c|c|c|c|c|c|}
\hline \multirow{2}{*}{ Species } & \multirow{2}{*}{ Catalase } & \multirow{2}{*}{$\begin{array}{l}\text { Beta-hemolysis } \\
\text { on sheep blood }\end{array}$} & \multirow{2}{*}{$\begin{array}{c}\text { Nitrate } \\
\text { reduction }\end{array}$} & \multirow{2}{*}{ Urease } & \multirow{2}{*}{$\begin{array}{c}\text { Esculin } \\
\text { hydrolysis }\end{array}$} & \multicolumn{5}{|c|}{ Fermentation of ${ }^{b}$ : } & \multirow{2}{*}{$\underset{\text { reaction }}{\text { CAMP }}$} \\
\hline & & & & & & Glu & Mal & Suc & Man & Xyl & \\
\hline A. neuii subsp. neuii & + & - & + & - & - & + & + & + & + & + & + \\
\hline A. neuii subsp. anitratus & + & - & - & - & - & + & + & + & + & + & + \\
\hline A. bovis & - & $\mathbf{V}^{c}$ & - & - & V & + & V & + & - & - & $\mathrm{ND}^{d}$ \\
\hline A. naeslundii & V & - & V & $+^{f}$ & + & + & + & + & $\mathrm{V}$ & V & - \\
\hline A. viscosus & + & - & + & $\mathrm{V}$ & V & + & + & + & - & V & - \\
\hline "A. suis" & - & ND & + & ND & ND & + & + & + & V & - & ND \\
\hline A. pyogenes & - & + & - & - & - & + & V & V & $\mathrm{V}$ & + & - \\
\hline A. odontolyticus & - & - & + & - & V & + & V & + & - & V & - \\
\hline A. hyovaginalis & - & - & + & - & + & + & + & + & ND & + & ND \\
\hline A. israelii & - & - & V & - & + & + & + & + & V & + & - \\
\hline A. gerencseriae & - & - & V & - & + & + & + & + & V & V & ND \\
\hline A. georgiae & - & - & V & - & V & + & + & + & V & + & ND \\
\hline A. meyeri & - & - & - & $\mathrm{V}$ & - & + & V & + & - & + & ND \\
\hline A. hordeovulneris & $(+)$ & ND & - & - & + & + & + & ND & - & + & ND \\
\hline A. haemolyticum & - & + & - & - & - & + & + & $\mathbf{V}$ & - & - & $\operatorname{Rev}^{g}$ \\
\hline
\end{tabular}

${ }^{a}$ Data were compiled from reference $4,8,11$, and 14 and unpublished data.

b Abbreviations: Glu, glucose; Mal, maltose; Suc, sucrose; Man, mannitol; Xyl, xylose.

$c \mathrm{~V}$, variable.

d ND, no data.

$e$ Genospecies 1 and 2.

$f$ Often weak or delayed reaction.

$g$ Rev, reverse CAMP reaction. 
neuii subsp. anitratus is proposed for $\mathrm{CDC}$ group 1-like strains.

Actinomyces neuii subsp. neuii sp. nov. $A$. neuii (neu'.ii. N. L. gen. n. neuii, of Neu, named to honor Harold Neu, an authority in antimicrobial chemotherapy and infectious diseases). This description of morphological and physiological features is based on a study of 17 strains (references 7 and 12 and unpublished data).

Cells are gram positive and predominantly diphtheroidal, but coccobacilli may occur; the rods are mainly arranged in clusters or $\mathrm{V}$ or $\mathrm{Y}$ forms. Cells are nonmotile and non-spore forming. Colonies are circular, smooth, convex, opaque, more white than creamy in color, and with entire edges. Colony sizes range from 0.5 to $1.5 \mathrm{~mm}$ in diameter after $48 \mathrm{~h}$ of incubation in $5 \% \mathrm{CO}_{2}$ on sheep blood agar. Cells are facultatively anaerobic. Alpha-hemolysis is observed for most strains on sheep blood agar and for all strains on human blood agar. Cells are catalase positive. Acid is produced from D-arabitol, erythritol, D-fructose, D-galactose, 5-ketogluconate, D-glucose, glycerol, inositol, lactose, D-lyxose, maltose, D-mannitol, D-mannose, melezitose, melibiose, raffinose, D-ribose, sucrose, trehalose, and D-xylose. Some strains produce acid from $N$-acetylglucosamine, adonitol, L-arabitol, L-arabinose, cellobiose, dulcitol, D-fucose, L-fucose, gentiobiose, gluconate, $\alpha$-methyl-D-glucoside, glycogen, inulin, $\alpha$-methyl-D-mannoside, D-tagatose, and xylitol. Acid is not produced from D-arabinose, 2-ketogluconate, L-rhamnose, salicin, D-glucitol, L-sorbose, and L-xylose. Leucine arylamidase, $\alpha$-galactosidase, $\beta$-galactosidase, $\alpha$-glucosidase, $\alpha$-mannosidase, and pyrazinamidase are positive. Alkaline phosphatase, valine arylamidase, trypsin, chymotrypsin, acid phosphatase, $\beta$-glucuronidase, and $\beta$-glucosidase are negative. Esculin, urea and gelatin are not hydrolyzed. Nitrate is reduced to nitrite. Straight-chain saturated fatty acids are mainly palmitic and stearic acids. Oleic acid is the predominant unsaturated fatty acid. DNA base composition is 55 to $58 \mathrm{~mol} \% \mathrm{G}+\mathrm{C}$ (midpoint temperature). The strains are isolated mainly from abscesses in association with mixed anaerobic flora as well as from human blood cultures. The type strain $97 / 90$ has been deposited in the Deutsche Sammlung für Mikroorganismen, Braunschweig, Germany, under no. DSM 8576. Strain 97/ $90^{\mathrm{T}}$ has the characteristics described for the species, except that, in the variable carbohydrate fermentation tests, only gentiobiose, $\alpha$-methyl-D-glucoside, and xylitol are positive. The $\mathrm{G}+\mathrm{C}$ content of strain $97 / 90^{\mathrm{T}}$ 's DNA is $55 \mathrm{~mol} \%$.

Actinomyces neuii subsp. anitratus subsp. nov. $A$. neuii subsp. anitratus (a.ni.tra'.tus. Gr. pref. $a$, not; L.n. nitratus, nitrate; M.L. adj. anitratus, not reducing nitrate). The following description of morphological and physiological features is based on nine strains (reference 7 and unpublished data).

The morphological characteristics of $A$. neuii subsp. anitratus are similar to those of $A$. neuii subsp. neuii, except that $A$. neuii subsp. anitratus is nonhemolytic. Cells are catalase positive. Acid is produced from adonitol, D-arabitol, erythritol, D-fructose, D-galactose, 5-ketogluconate, D-glucose, $\alpha$-methyl-D-glucoside, glycerol, inositol, lactose, D-lyxose, maltose, D-mannitol, D-mannose, melezitose, melibiose, raffinose, D-ribose, sucrose, trehalose, and D-xylose. Some strains produce acid from $N$-acetylglucosamine, L-arabitol, cellobiose, dulcitol, D-fucose, L-fucose, gentiobiose, gluconate, glycogen, salicin, and D-tagatose. Acid is not produced from $\mathrm{D}$-arabinose, L-arabinose, 2-ketogluconate, inulin, $\alpha$-methyl-D-mannoside, L-rhamnose, D-glucitol, L-sorbose, xylitol, and L-xylose. Leucine arylamidase, $\alpha$-ga- lactosidase, $\beta$-galactosidase, $\alpha$-glucosidase, $\alpha$-mannosidase, and pyrazinamidase are positive. Alkaline phosphatase activity can be observed in some strains. Valine arylamidase, trypsin, chymotrypsin, acid phosphatase, $\beta$-glucuronidase, and $\beta$-glucosidase are negative. Esculin, urea, and gelatin are not hydrolyzed. Nitrate is not reduced to nitrite. Straight-chain saturated fatty acids are mainly palmitic and stearic acids. Oleic acid is the predominant unsaturated fatty acid. The DNA base composition is 55 to $58 \mathrm{~mol} \% \mathrm{G}+\mathrm{C}$ (midpoint temperature). The strains are isolated mainly from abscesses in association with mixed anaerobic flora as well as from human blood cultures. The type strain is strain 50/90 and has been deposited in the Deutsche Sammlung für Mikroorganismen under no. DSM 8577. Strain $50 / 90^{\mathrm{T}}$ has the characteristics described for the species, except that, in the variable carbohydrate fermentation tests, only $N$-acetylglucosamine, gluconate, and salicin are positive. The $\mathrm{G}+\mathrm{C}$ content of its DNA is $55 \mathrm{~mol} \%$.

\section{ACKNOWLEDGMENT}

M.D.C. and S.S. were supported by a grant from the EEC (HRAMI project, BIOT-CT91-0294 SSMA).

\section{REFERENCES}

1. Ausubel, F. M., R. Brent, R. E. Kingston, D. D. Moore, J. G. Seidman, J. A. Smith, and K. Struhl. 1989. Current protocols in molecular biology. John Wiley and Sons, Chichester, United Kingdom.

2. Böddinghaus, B., J. Wolters, W. Heikens, and E. C. Böttger. 1990. Phylogenetic analysis and identification of six different serovars of Mycobacterium intracellulare at the molecular level. FEMS Microbiol. Lett. 70:197-204.

3. Brosius, J., M. L. Palmer, P. J. Kennedy, and H. F. Noller. 1978. Complete nucleotide sequence of a 16S ribosomal RNA gene from Escherichia coli. Proc. Natl. Acad. Sci. USA 75:48014805 .

4. Collins, M. D., S. Stubbs, J. Hommez, and L. A. Devriese. 1993. Molecular taxonomic studies of Actinomyces-like bacteria isolated from purulent lesions in pigs and description of Actinomyces hyovaginalis sp. nov. Int. J. Syst. Bacteriol. 43:471-473.

5. Felsenstein, L. 1982. Numerical methods for inferring evolutionary trees. Q. Rev. Biol. 57:379-404.

6. Fitch, W. M., and E. Margoliash. 1967. Construction of phylogenetic trees: a method based on mutation distances as estimated from cytochrome $c$ sequences is of general applicability. Science 155:279-284.

7. Funke, G., G. Martinetti Lucchini, G. E. Pfyffer, M. Marchiani, and A. von Graevenitz. 1993. Characteristics of CDC group 1 and group 1-like coryneform bacteria isolated from clinical specimens. J. Clin. Microbiol. 31:2907-2912.

8. Hollis, D. G., and R. E. Weaver. 1981. Gram-positive organisms: a guide to identification. Special Bacteriology Section, Centers for Disease Control, Atlanta.

9. Hori, H., and S. Osawa. 1979. Evolutionary change in 5S rRNA secondary structure and phylogenetic tree of 54 5S rRNA species. Proc. Natl. Acad. Sci. USA 76:381-385.

10. Hutson, R. A., D. E. Thompson, and M. D. Collins. 1993. Genetic interrelationships of saccharolytic Clostridium botulinum types $\mathrm{B}, \mathrm{E}$ and $\mathrm{F}$ and related clostridia as revealed by small-subunit rRNA gene sequences. FEMS Microbiol. Lett. 108:103-110.

11. Johnson, J. L., L. V. H. Moore, B. Kaneko, and W. E. C. Moore. 1990. Actinomyces georgiae sp. nov., Actinomyces gerencseriae sp. nov., designation of two genospecies of Actinomyces naeslundii, and inclusion of $A$. naeslundii serotypes II and III and Actinomyces viscosus serotype II in $A$. naeslundii genospecies 2. Int. J. Syst. Bacteriol. 40:273-286.

12. Na'was, T. E., D. G. Hollis, C. W. Moss, and R. E. Weaver. 1987. Comparison of biochemical, morphologic, and chemical characteristics of Centers for Disease Control fermentative 
coryneform groups 1, 2, and A-4. J. Clin. Microbiol. 25:1354 1358.

13. Queen, C., and L. J. Korn. 1984. A comprehensive sequence analysis program for the IBM personal computer. Nucleic Acids Res. 12:581-599.

14. Schaal, K. P. 1986 . Genus Actinomyces Harz $1877,133^{\mathrm{AL}}$, p. 1383-1418. In P. H. A. Sneath, N. S. Mair, M. E. Sharpe, and J. G. Holt (ed.), Bergey's manual of systematic bacteriology, vol. 2. Williams and Wilkins, Baltimore.

15. Stackebrandt, E., and O. Charfreitag. 1990. Partial 16S rRNA primary structure of five Actinomyces species: phylogenetic implications and development of an Actinomyces israeliispecific oligonucleotide probe. J. Gen. Microbiol. 136:37-43.

16. Wayne, L. G., D. J. Brenner, R. R. Colwell, P. A. D. Grimont, O. Kandler, M. J. Krichevsky, L. H. Moore, W. E. C. Moore, R. G. E. Murray, E. Stackebrandt, M. P. Starr, and H. G. Trüper. 1987. Report of the ad hoc committee on reconciliation of approaches to bacterial systematics. Int. J. Syst. Bacteriol. 37:463-464. 